\title{
Tipps und Tricks: Fasszange von Schraubenköpfen ohne Blockade
}

$\square$ Dankward Höntzsch

Es gibt eine Fasszange, die hilft, Schrauben herauszudrehen, welche sich nicht von allein zurückdrehen wollen, sondern gleichzeitig zum Drehen zurückgezogen werden müssen.
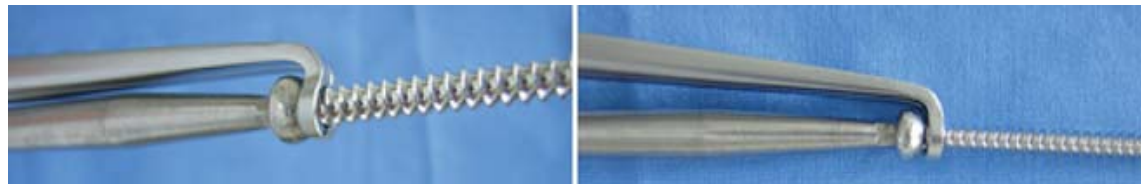

Die Zange fasst den Schraubenschaft knapp unter dem Kopf, ohne ihn zu blockieren, und der Schaft verläuft parallel zum Schraubenzieher.

Diese Zange kann auch zum Einbringen in der Tiefe von Schrauben verwendet
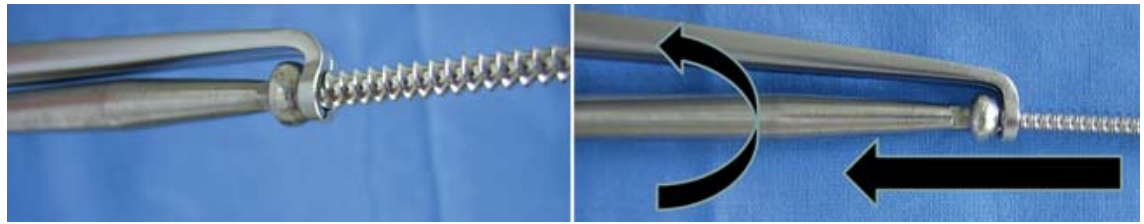
werden. 